\title{
The clinical response to treatment in adult Cushing's syndrome following remission of hypercortisolaemia
}

\author{
E.J. Ross and D.C. Linch \\ Department of Medicine, Faculty of Clinical Sciences, University College, and University College Hospital, \\ London, UK.
}

\begin{abstract}
Summary: The clinical response of 57 adult patients with Cushing's syndrome due to bilateral adrenocortical hyperplasia or adrenocortical adenoma is documented following resolution of hypercortisolaemia by various forms of treatment. Despite satisfactory biochemical remission of the disease the clinical result was far less satisfactory when assessed by persistence of obesity (55\%), menstrual irregularity (41\%), hypertension (29\%) and insulin-dependent diabetes (22\%). Myopathy, hirsuitism and psychological abnormalities persisted to a lesser extent. The mortality rate of the series over a 30 year follow-up period was 4 times that of a general population matched for sex, age and year of entry into the series. Cardiovascular disease was the cause of death in $85 \%$. Irreparable cardiovascular disease is produced early in the course of hypercortisolaemia, emphasizing the vital importance of the earliest possible recognition and treatment of this disease.
\end{abstract}

\section{Introduction}

The outlook for patients with Cushing's syndrome due to non-malignant adrenal disease has improved greatly in the last 30 years following the introduction of a variety of procedures aimed at reduction of the excessive cortisol production.

Pituitary irradiation alone controlled hypercortisolaemia satisfactorily in less than half (Soffer $e t$ al., 1955; Orth \& Liddle, 1971; Scott et al., 1977) but the advent of bilateral adrenalectomy and, more recently, of pituitary microsurgery has ensured that hypercortisolaemia can be controlled in nearly all cases (Cope \& Raker, 1955; Ernest \& Ekman, 1972; KasperlikZaluska et al., 1978; Hardy, 1969; Urbanic \& George, 1981).

It is the purpose of this paper to emphasize that normalization of cortisol production is not necessarily followed by remission of the clinical features and that there is a continuing high morbidity and excessive mortality from the disease, largely due to persistence of the cardiovascular manifestations.

\section{Patients}

Fifty-seven patients above the age of $16 \mathrm{y}$ who had biochemically proven Cushing's syndrome due to nonmalignant disease have been treated at University

E.J. Ross, M.D., Ph.D., F.R.C.P.; D.C. Linch, M.B., B.S., M.R.C.P.

Accepted: 20 August 1984
College Hospital and personally followed-up for a period extending over $30 \mathrm{y}$. The diagnostic criteria of many of the earlier cases were reviewed in 1966 by Ross, Marshall-Jones and Friedman at a time when methods of diagnosis were not as precise as is currently possible and any equivocal cases from that series have been excluded in the present survey. These patients and later cases have all had sustained hypercortisolaemia, with loss of diurnal variation, increased urinary excretion of cortisol and resistance to suppression with dexamethasone.

Histological confirmation was obtained operatively in those who underwent adrenalectomy or pituitary microsurgery, but not in those treated by pituitary irradiation or drug therapy. There were 8 cases of adrenal adenoma and 49 cases with adrenocortical hyperplasia. Forty-nine of the 57 patients were female. No cases of adrenocortical carcinoma, the ectopic ACTH syndrome, or alcohol-dependent hypercortisolaemia have been included.

\section{Modes of treatment}

\section{Adrenocortical adenoma}

Seven of the 8 patients with unilateral adrenocortical adenoma were treated by resection of the affected gland. In the eight patients, investigations suggested the presence of adrenocortical adenoma but adrenal exploration revealed two atrophic adrenal glands. 
Extensive search within the abdominal cavity failed to reveal ectopic adrenal tissue but post-operatively all the biochemical and clinical features of Cushing's syndrome resolved, presumably due to infarction during surgery of an adenoma in an adrenal rest.

\section{Adrenocortical hyperplasia}

Forty-nine patients with adrenal hyperplasia have received treatment (Table I). Pituitary irradiation with 38-40 Gs $(3800-4000 \mathrm{r})$ was used to treat 23 patients. One of these patients required a second course of $40 \mathrm{Gs}$ because of continuing hypercortisolaemia. A further 5 patients who did not have an acceptable biochemical response received bilateral adrenalectomy at a later date. Total bilateral adrenalectomy was used as the sole treatment in 16 patients. In the early part of this series an intended subtotal adrenalectomy was performed in 5 cases; and in a further patient following an inadequate response to pituitary irradiation. In 2 of these 6 patients the adrenalectomy was effectively complete since the patients were never able to come off replacement therapy and showed no adrenal response to stimulation by corticotrophin.

\section{Results}

\section{Biochemical response to treatment}

All patients treated by bilateral adrenalectomy required long-term cortisol replacement therapy using hydrocortisone indicating the efficacy of the total adrenalectomy. The dose was adjusted to the lowest amount consistent with clinical well-being and satisfactory plasma cortisol concentration. The usual
Table I Modes of treatment used for adrenal hyperplasia in 49 patients

\begin{tabular}{lr}
\hline Pituitary irradiation & 23 patients \\
Bilateral adrenalectomy & 22 patients \\
Subtotal adrenalectomy & 4 patients \\
Drug therapy & 4 patients \\
Pituitary microsurgery & 5 patients
\end{tabular}

58 treatment courses were given to 49 patients.

maintenance dose was $20 \mathrm{mg}$ at $8 \mathrm{am}$ and $10 \mathrm{mg}$ at midday. Patients with adrenocorticol adenoma in whom a single adrenal gland was resected required replacement therapy initially for a varying period up to $1.5-2 \mathrm{y}$ and in 1 case permanently. In 16 of the 23 patients treated by pituitary irradiation cortisol production fell to normal as judged by $24 \mathrm{~h}$ urinary free cortisol excretion but diurnal variation of plasma cortisol concentration was rarely restored. Pituitary microsurgery effectively controlled the hypercortisolaemia in all cases and none has yet relapsed. Hypocortisolaemia requiring replacement therapy for periods up to 9 months occurred after microsurgery. No adult patient has had an adequate lasting biochemical response to drug therapy by cyproheptidine, bromocriptine or metyrapone.

\section{Clinical response to treatment}

Assessment of clinical response to treatment (see Table II) must necessarily be subjective and has been assigned to one of four categories on the basis of the degree of remission of hypertension, diabetes, obesity, menstrual and psychological derangement, hirsutism, myopathy and ability to resume their previous occupa-

Table II Clinical response to treatment (excluding pituitary microsurgery).

\begin{tabular}{lccccc}
\hline Pathology and treatment & Excellent & Good & $\begin{array}{c}\text { Response } \\
\text { Fair }\end{array}$ & Poor & Total \\
\hline $\begin{array}{l}\text { Adenomas } \\
\text { Unilateral adrenalectomy }\end{array}$ & 0 & 4 & 1 & 3 & 8 \\
Bilateral hyperplasia & 1 & 8 & 5 & 9 & 23 \\
Pituitary irradiation & 2 & 8 & 5 & 5 & 20 \\
Total adrenalectomy & 1 & 2 & 0 & 1 & 4 \\
Subtotal adrenalectomy & 0 & 0 & 0 & 4 & 59 \\
Drug therapy & 4 & 22 & 11 & 22 & \\
\hline Total number of treatments & & &
\end{tabular}

59 treatment regimens were given to 54 patients. Overall, 26 of 54 patients ultimately had an excellent or good clinical response to treatment. Two patients with bilateral adrenal hyperplasia, treated by total adrenalectomy, died within 3 months and are not included in this analysis. 
tion. Persistence of osteoporosis was not included as it seldom resolves completely in adults and is difficult to quantitate in ageing female patients.

Excellent: complete remission of all signs and symptoms.

Good: resolution of all but one aspect of the disease complex.

Fair: partial improvement of all signs and symptoms or complete resolution of all but 2 features.

Poor: minimal improvement only in all signs and symptoms or failure of at least 3 features of the disease to remit. This category also includes deaths in the perioperative period.

\section{Adrenocortical adenoma}

Four out of 8 patients had a good response and 4 had only a fair or poor response, one of the latter being a postoperative death. Seven of these patients had hypertension and this remitted completely in only one patient.

\section{Bilateral adrenal hyperplasia: Pituitary irradiation}

There was only one complete remission in the 23 patients so treated. Nine patients had a good clinical response, although one of these relapsed 2 years later and required bilateral adreralectomy. Five patients had a fair response but 9 patients responded poorly. The five patients who subsequently required bilateral adrenalectomy because of persistent hypercortisolaemia all had a poor clinical response.

\section{Bilateral adrenalectomy}

Twenty-two patients were treated by bilateral adrenalectomy (although 2 were intended to be only subtotal). Three of these patients died within 6 months. One death was in the early postoperative period; the cause for this was not established. Another died 2 months after surgery from a cerebrovascular accident and bronchopneumonia; there had been a poor clinical response to adrenalectomy up to the time of death. The third death 6 months postoperatively occurred in a patient who had shown a good clinical response to treatment and was due to a viral disease complicated by acute adrenal insufficiency. In the other 17 patients response was excellent in 2, good in 8, fair in 5 and poor in 2.

\section{Subtotal adrenalectomy}

Four patients were subtotally adrenalectomized. The clinical response was excellent in 1 , good in 2 and poor in 1. Despite these satisfactory results this method of treatment was soon abandoned because of the high incidence of relapse reported from other centres.

\section{Drug treatment}

All 4 patients responded poorly, both biochemically and clinically and have now been treated by bilateral adrenalectomy ( 1 case) or pituitary microsurgery.

\section{Pituitary microsurgery}

The clinical response of the 5 patients cannot yet be fully assessed as follow-up is short and they are not therefore included in Table II. All responded promptly by reduction of cortisol secretion; and the clinical response to date has been encouraging.

\section{Factors affecting overall clinical response}

The clinical response to unilateral adrenalectomy for adenoma was similar to that in bilateral adrenalectomy for adrenal hyperplasia, with $57 \%$ of the patients with adenoma and $54 \%$ of patients with hyperplasia having an excellent or good response. The adenoma patients have ultimately survived for a shorter period because hypertension was the feature that persisted (see below). The clinical response to pituitary irradiation in bilateral hyperplasia was unsatisfactory, with only $39 \%$ having an excellent or good response. The

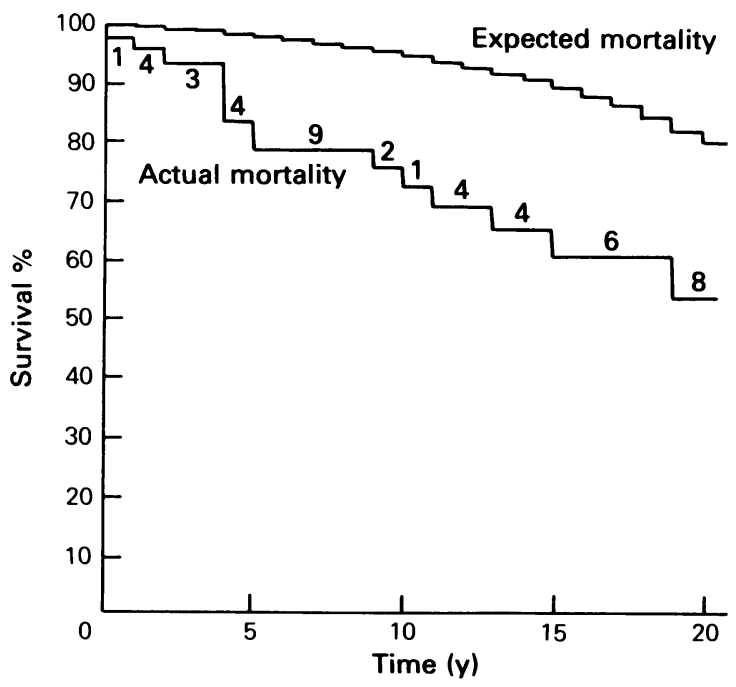

Figure 1 The survival curve for the 46 adult females with treated Cushing's syndrome is shown above. The expected mortality for an age, sex and year of entry matched control population is shown (Registrar General, UK). 
patients receiving treatment by these two procedures were comparable, the average age being $39.3 \mathrm{y}$ in those treated by pituitary irradiation and $40.7 \mathrm{y}$ in those treated by bilateral adrenalectomy.

It will be seen from Table III that the average age of those patients having an excellent or good response to all forms of treatment was significantly lower than those having a fair or poor response $(P<0.05)$. This age dependency in response is seen in both those treated by pituitary irradiation and in those treated by adrenalectomy.

\section{Response of individual features}

Hypertension Defined as a diastolic pressure persistently exceeding $90 \mathrm{~mm} \mathrm{Hg}$, hypertension was present in $79 \%$ of patients in this series. Following treatment it remitted completely in $45 \%$ and partially (i.e. became more easily controlled by anti-hypertensive agents) in $26 \%$. It was more severe in those with adrenocortical adenoma than in those with hyperplasia, the mean blood pressure being $188 / 112 \mathrm{~mm} \mathrm{Hg}$ in the former and $169 / 103$ in the latter.

Glucose intolerance Overt insulin-dependent diabetes remitted completely in $67 \%$, partially (i.e. required a reduced dose of insulin) in $11 \%$ but remained unchanged in $22 \%$. In only one of the latter category was it difficult to control.

Menstrual problems Twenty-two women under the age of $\mathbf{4 0}$ were being treated. Nine of these have had a total of 17 pregnancies following treatment. These include 3 spontaneous abortions and 3 terminations of pregnancy, 2 for psychiatric and 1 for social reasons. The eleven live births presented no obstetric difficulties and all the children are normal. Four of these mothers had been treated by pituitary irradiation alone, 4 by bilateral adrenalectomy and 1 by resection of an adrenal adenoma.
Obesity Defined as body weight above $115 \%$ of ideal, obesity persisted in $55 \%$ of these patients following treatment.

\section{Mortality}

Two patients died in the immediate postoperative period following total adrenalectomy for adrenal hyperplasia in one case and removal of an adrenal adenoma in the other. The immediate operative mortality was $3.8 \%$. Two patients with bilateral adrenal hyperplasia died 2 months and 6 months postoperatively, one from pneumonia and the other from adrenal insufficiency complicating a virulent viral infection. A fifth patient with bilateral hyperplasia died from hepatorenal failure.

Fifty of the remaining patients in this study survived beyond the 1st year of their definitive treatment and have been followed over a period of up to $30 \mathrm{y}$. No deaths have occurred among the 4 males. Forty-six female patients have a total follow-up period of 531 y which allows statistical analysis of the late mortality to be performed. The number of deaths expected in a general population during this period has been estimated from the sum of the yearly crude mortality rates at the year of entry to the series, and the age and sex of the patient. The expected number of deaths was 4 , compared with the actual number in the series of 160 The percentage mortality in the series compared with matched general population over a corresponding $20 y$ period is compared in the figure. It should be noted that the excess mortality occurred mainly in the first $5 \mathrm{y}$ after treatment. Thirteen of the $\mathbf{1 6}$ deaths were due to cardiovascular disease (81\%) (see Table IV). One death was due to suicide $2 y$ after removal of an adrenal adenoma in a seriously disturbed patient, one was due to pulmonary embolism $20 \mathrm{y}$ after adrenalectomy. The remaining patient died in another hospital and no cause was found at autopsy.

Table III Effect of age and treatment mode on clinical response in adrenal hyperplasia

\begin{tabular}{|c|c|c|c|c|c|}
\hline \multirow{3}{*}{ Treatment } & \multicolumn{4}{|c|}{ Response } & \multirow[t]{3}{*}{ Total Number } \\
\hline & \multirow{2}{*}{\multicolumn{2}{|c|}{$\begin{array}{l}\text { Excellent and Good } \\
\text { (n) Mean age }\end{array}$}} & \multicolumn{2}{|c|}{ Poor and Fair* } & \\
\hline & & & & Mean age & \\
\hline $\begin{array}{l}\text { Pituitary } \\
\text { irradiation }\end{array}$ & 9 & $\begin{aligned} & 34.3 \mathrm{y} \\
\pm & 13.8 \text { s.d. }\end{aligned}$ & 14 & $\begin{array}{c}43.3 \mathrm{y} \\
\pm 10.8 \mathrm{s.d}\end{array}$ & 23 \\
\hline \multirow[t]{2}{*}{$\begin{array}{l}\text { Adrenalectomy } \\
\text { (total and subtotal) }\end{array}$} & 13 & $\begin{array}{c}37.6 \mathrm{y} \\
\pm \quad 9.1 \text { s.d. }\end{array}$ & 11 & $\begin{array}{c}45.6 y \\
\mu 15.8 \text { s.d. }\end{array}$ & 24 \\
\hline & 22 & $\begin{aligned} & 36.3 y \\
\pm & 11.0 \text { s.d. }\end{aligned}$ & 27 & $\begin{array}{c}44.1 \text { y } \\
\pm 12.5 \text { s.d. }\end{array}$ & 49 \\
\hline
\end{tabular}

\footnotetext{
* Two perioperative deaths included
} 
Table IV Deaths in treated patients during follow-up period.*

\begin{tabular}{lllllll}
\hline Patient & $\begin{array}{l}\text { Age on } \\
\text { entry }(y)\end{array}$ & $\begin{array}{l}\text { Adrenal } \\
\text { abnormality }\end{array}$ & $\begin{array}{l}\text { Blood pressure } \\
\text { on entry } \\
(\mathrm{mm} \text { Hg) }\end{array}$ & Treatment & $\begin{array}{l}\text { Survival time } \\
(y)\end{array}$ & Cause of death \\
\hline 1 & 32 & hyperplasia & $140 / 95$ & bilat. adrenalectomy & 20 & hypertension, pulm. \\
& & embolus & CVA \\
4 & 49 & adenoma & $150 / 100$ & resection & 7 & CVA \\
6 & 34 & hyperplasia & $150 / 100$ & bilat. adrenalectomy & 16 & CVA \\
11 & 46 & hyperplasia & $230 / 140$ & bilat. adrenalectomy & 3 & CVA \\
16 & 45 & hyperplasia & $235 / 130$ & bilat. adrenalectomy & 5 & CVA \\
23 & 45 & adenoma & $190 / 100$ & resection & 2 & unknown \\
24 & 60 & hyperplasia & $230 / 130$ & bilat. adrenalectomy & 4 & CCF \\
32 & 50 & hyperplasia & $195 / 125$ & bilat. adrenalectomy & 8 & MI \\
35 & 56 & hyperplasia & $180 / 100$ & pit. irradiation & 11 & CVA \\
36 & 59 & hyperplasia & $220 / 100$ & pit. irradiation & 10 & resp. failure \\
38 & 24 & hyperplasia & $170 / 110$ & bilat. adrenalectomy & 5 & CVA \\
42 & 46 & hyperplasia & $230 / 150$ & unilat. adrenalectomy & 7 & CVA \\
45 & 39 & hyperplasia & $190 / 120$ & pit. irradiation & 3 & CCF \\
48 & 48 & hyperplasia & $160 / 95$ & pit. irradiation & 14 & suicide \\
59 & 50 & adenoma & $160 / 100$ & resection & 2 & CVA \\
65 & 34 & adenoma & $210 / 110$ & resection & 1 & \\
\end{tabular}

* Peri-operative deaths omitted. CVA - cerebrovascular accident. CCF - congestive heart failure. MI - myocardial infarction

\section{Discussion}

Treatment by pituitary irradiation resulted in biochemical remission in $69 \%$ of our patients but a prolonged clinical remission occurred in only $50 \%$ of those with normalized cortisol secretion. This is in agreement with the results of Dohan et al. (1957); Soffer et al. (1961); Orth \& Liddle (1971) and Scott $e$ t al. (1977). This form of treatment when successful, also had the disadvantage of slow resolution of the clinical features of the disease, but has the advantage of non-dependence on subsequent replacement therapy.

Although bilateral adrenalectomy had the advantage of curing hypercortisolaemia in virtually all patients, there was a significant mortality within the first year of $8 \%$ including a perioperative mortality of $3.8 \%$. An early mortality of up to $25 \%$ appears in various published series (Sprague et al., 1961; Welbourn et al., 1971; Ernest \& Ekman, 1972; Scott et al., 1977; Urbanic \& George, 1981; Tomita et al., 1981; Skalkeas et al., 1982, Pelkonen et al., 1983). This perioperative mortality can now be minimized by preoperative preparation with metyrapone or other inhibitors of cortisol synthesis, together with advances in surgical and anaesthetic techniques including antibiotics. The disadvantages of this form of treatment, apart from the operative mortality and morbidity, include life-long hydrocortisone replacement therapy and constant vigilance on the part of the patient to recognize situations requiring adjustment of replacement therapy. Enlargement of a pituitary adenoma following adrenalectomy occurred in only one of our patients $(4.2 \%)$, but the prevalence of this complication is often higher in other series (Kelly et al., 1983).

Adrenalectomy has been largely displaced by pituitary adenomectomy in patients with pituitarydependent hypercortisolaemia (Hardy, 1969). A recent report by Boggan et al. (1983) claims correction of hypercortisolaemia in 78 of 100 patients with subsequent relapse in four. Sixty-two patients are stated to have had long term remission but no analysis of clinical response is given. In our limited experience this procedure succeeds in reducing cortisol secretion within one or two days, necessitating glucocorticoid replacement therapy for varying periods up to 9 months when endogenous secretion recovers. All our patients treated by pituitary microsurgery suffered severe post-operative depression with constant complaints of weakness, muscle pain, tiredness and loss of energy; they were reluctant to return to work or resume their household activity for several months, when this post-operative malaise abruptly remitted. Three of our 5 patients so far have had a good response to treatment, in accordance with the reports of other small series, although results are very variable (Burch, 1983).

Patients with adrenocortical adenoma responded to treatment by resection in a similar manner to those 
with bilateral hyperplasia, a successful clinical response being achieved in $54 \%$ of those with bilateral hyperplasia and $50 \%$ of those with adrenal adenoma. One of the adenoma patients died from cerebrovascular disease and one committed suicide $2 \mathrm{y}$ postoperatively. The series published by Välimäki et al. (1984), also contained 1 postoperative suicide among 14 patients. The serious psychological involvement of patients with adrenal adenoma and hence suppressed pituitary secretion of corticotrophin throws doubt on the views of Starkman and Schteingart (1981) concerning the role of corticotrophin in the cause of the mental depression so common in this disease.

When treament results in successful control of hypercortisolaemia, it might be expected that clinical remission would follow. Although 'cure' is often claimed, detailed clinical information is frequently lacking. Complete remission of all manifestations of the disease in our experience occurs in a minority of patients, less than $10 \%$ in our series. Resolution of all but one feature occurred in $\mathbf{4 8 \%}$. Important manifestations which failed to resolve were hypertension, carbohydrate intolerance and obesity.

Hypertension persisted in $70 \%$ of our patients, although usually to a less severe degree. In their informative report of the results of adrenalectomy Ernest and Ekman (1972) noted that 14 of their 21 patients remained hypertensive. Welbourn et al. (1970) and Urbanic and George (1981) report persistence of hypertension in about one third of their patients.

Impaired glucose tolerance present pre-operatively in 18 of our patients remitted completely in $67 \%$ and partially in $11 \%$. In 17 of those patients it coexisted with hypertension. Welbourn et al. (1971) noted that all their mildly diabetic patients became normoglycaemic after adrenalectomy, as did one of two severely diabetic patients.

Obesity responds poorly to definitive treatment of Cushing's syndrome, about $50 \%$ remaining obese. Although some may lose weight within the first year or two after treatment, most regain this weight with prolonged follow-up. This accords with the observation of Ernest and Ekman (1972) who found that only 12 of their 25 patients on prolonged follow-up had lost weight, and of Urbanic and George (1981) in whose series $42 \%$ remained obese. Although failure to lose weight is often regarded (by the doctor, not the patient) as of minor importance, it is a recognized risk factor aggravating candiovascular disease.
Review of this series of patients with hypercortisolaemia and the reports of others have emphasized $\varrho$ that this is still a potentially lethal disease, the mortality in our patients being 4 times that of a similar 2

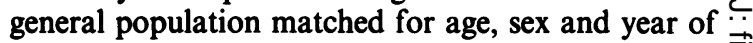
entry. Cardiovascular disease accounted for $81 \%$ of $\overrightarrow{\overline{\vec{O}}}$ the deaths in this series, death occurring mainly in the -0 first $5 \mathrm{y}$ following definitive treatment. Hypertension $\frac{C}{0}$ at time of diagnosis was a serious obstacle to prolon- $\overline{\bar{c}}$ ged survival. Twelve of the 30 patients who remained $\widehat{\nabla}$ hypertensive after treatment subsequently died of cerebrovascular disease ( 9 patients), congestive heart ${ }^{2}$ failure (2), myocardial infarction (1) and pulmonary $\vec{\circ}$ embolism (1). These mortality figures underline the $\overrightarrow{\vec{\omega}}$ severe hypertension which may dominate the clinical picture and persist despite correction of hypercort- $\overrightarrow{0}$ isolaemia and vigorous treatment with antihyperten- 3 sive agents. Welbourn et al. (1972) reported that cardiovascular disease was the major cause of death $\vec{\nu}$ with the first year following adrenalectomy, 5 of their $\vec{\omega}$ 25 patients dying from this complication. During i subsequent follow-up 7 of 10 deaths in their 41 or

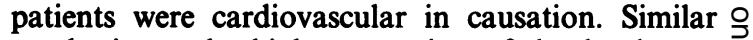
emphasis on the high proportion of deaths due to cardiovascular disease has been made by Sprague et al. 3 (1961), Ernest and Ekman (1972) and Valimaki et al. (1984).

The 5 y survival in this series of $77 \%$ is certainly a $\overrightarrow{0}$ improvement on the outcome in untreated patien of where the 5 y survival is approximately $50 \%$ (Plotz al., 1952; Sprague et al., 1961).

The frequent poor clinical response to treatment and the high mortality from cardiovascular complications in this disease is, however, disturbing. The $\frac{D}{\mathbb{D}}$ average duration of symptoms before diagnosis in this series was $5 \mathrm{y}$. It is hoped that earlier diagnostic consideration of the possibility of hypercortisolaemia will result in speedier treatment before irreparable vascular damage has occurred. Restoration to normal cortisol secretion by the various forms of treatment currently available is easy. To produce a lasting clinical remission is more difficult.

\section{Acknowledgements}

The authors wish to thank all those who have referred cases $D$ for diagnosis and treatment. Professor M. Stone of the Department of Statistical Science, University College Lon- $\vec{N}$ don, devised the method used in the statistical analysis of $\mathrm{N}$ these patients; this will be published by him separately.

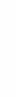


References

BOGGAN, J.E., TYRRELL, J.B. \& WILSON, C.B. (1983). Transsphenoidal microsurgical management of Cushing's disease. Journal of Neurosurgery, 59, 195.

BURCH, W. (1983). A survey of results with transsphenoidal surgery in Cushing's disease. New England Journal of Medicine, 308, 103.

COPE, O. \& RAKER, J.W.. (1955). Cushing's disease. New England Journal of Medicine, 253, 165.

DOHAN, F.C., RAVENTOS, A., BOUCOT, N. \& ROSE, E. (1957). Roentgen therapy in Cushing's syndrome without adrenocortisol tumour. Journal of Clinical Endocrinology and Metabolism, 17, 8.

ERNEST, I. \& EKMAN, H. (1972). Adrenalectomy in Cushing's disease. Acta Endocrinologica, 69, Suppl. 160. 15.

HARDY, J. (1969). Transsphenoidal microsurgery of the normal and pathological pituitary. Clinical Neorosurgery, $16,195$.

KASPERLIK-ZALUSKA, A., HARTWIG, W., NIELBUOWICZ, J., RUDOWSKI, W., MIGDALSKA, B., BOBUSZEWSKAFARYNA, M. \& ZALUSKA, J. (1978). Clinical analysis of 111 cases of adrenocortical hyperfunction. Results of surgical treatment. Endokrynologia Polska, 29, 273.

KELLY, W.F., MACFARLANE, I.A., LONGSON, D., DAVIES, D. \& SUTCLIFFE, H. (1983). Cushing's disease treated by total adrenalectomy: long term observation of 43 patients. Quarterly Journal of Medicine, 52, 224.

ORTH, D.N. \& LIDDLE, G.W. (1971). Results of treatment in 108 patients with Cushing's syndrome. New England Journal of Medicine, 285, 243.

PELKONEN, R., EISTOLA, P., GRAHNE, B., KUVISTO, A., PAETAU, A., SIVULA, A. \& VALTONEN, S. (1983). Treatment of pituitary Cushing's disease: results of adrenal and pituitary surgery. Acta Endocrinologica, 102, Suppl 251, 38.

PLOTZ, C.M., KNOWLTON, A.I. \& RAGAN, C. (1952). The natural history of Cushing's syndrome. American Journal of Medicine, 13, 597.

REGISTRAR GENERAL (UK). Dicennial Supplement En- gland and Wales Life Tables. Report on Life Tables by Government Actuary (1961) Appendix IV, 28 and (1971) Appendix II, 13.

ROSS, E.J., MARSHALL-JONES, P. \& FRIEDMAN, M. (1966). Cushing's syndrome: diagnostic criteria. Quarterly Journal of Medicine, 35, 149.

SCOTT, H.W., LIDDLE, G.W., MULHERIN, J.L., MCKENNA, T.J., STROUP, S.L. \& RHAMY, R.K. (1977). Surgical experience with Cushing's disease. Annals of Surgery, 185, 524.

SKALKEAS, G., GOGAS, J.G., SECHAS, M.N., KOSTAKIS, A.\& PAVLATOS, F. (1982). Cushing's syndrome. Analysis of 18 cases. American Journal of Surgery, 143, 363.

SOFFER, L.J., IANNACCONE, A. \& GABRILOVE, J.C. (1961). Cushing's syndrome: a study of 50 patients. American Journal of Medicine, 30, 129.

SPRAGUE, R.G., RANDALL, R.V. \& SALASSA, R.M. (1956). Cushing's syndrome. Review of 100 cases. Archives of Internal Medicine, 98, 389.

STARKMAN, M.N. \& SCHTEINGART, D.E. (1981). Neuropsychiatric manifestations in patients with Cushing's syndrome. Archives of Internal Medicine, 141, 215.

TOMITA, A., SUZUKI, S., HARA, I., YUTAKA, O., MIZUNO, S., YOGO, H., KUWAYAMA, A. \& KAGEYAMA, N. (1981). Follow-up study on treatment in 27 patients with Cushing's disease: adrenalectomy, transsphenoidal adrenomectomy and medical treatment. Endocrinologia Japonica, 28, 197.

URBANIC, R.C. \& GEORGE, J.M. (1981). Cushing's disease: 18 years experience. Medicine (Baltimore), 60, 14.

VÄLIMÄKI, M., PELKONEN, R., PORKKA, L., SIVULA, A. \& KAHRI, A. (1984). Long-term results of adrenal surgery in patients with Cushing's syndrome due to adrenocortical adenoma. Clinical Endocrinology, 20, 229.

WELBOURN, R.B., MONTGOMERY, D.A.D. \& KENNEDY, T.L. (1971). The natural history of treated Cushing's syndrome. British Journal of Surgery, 58, 1. 